\title{
ROBESPIERRE Y EL TERROR DEL AÑO II: PODER Y VIOLENCIA DURANTE EL GOBIERNO REVOLUCIONARIO*
}

\author{
ROBESPIERRE AND THE TERROR OF THE YEAR II: POWER \\ AND VIOLENCE DURING THE REVOLUTIONARY \\ GOVERNMENT
}

\author{
Juan Carlos Medel Toro** \\ "Dilucidar el desencadenamiento de la violencia significa explicar la marcha de las revoluciones. \\ Descubrir una ética de la violencia, significa justificar la revolución"
}

Albert Soboul ${ }^{1}$

\section{RESUMEN}

Durante el año II (julio de 1793-junio de 1794) de la Revolución francesa, Maximilien Robespierre, lider de los Jacobinos, dirigió los destinos de la naciente república. Fuertemente influenciado fillosófica y politicamente por Jean Jacques Rousseau, Robespierre ejerció el poder a través de discursos en la Asamblea Legislativa y practicando la violencia revolucionaria como medio de salvaguardar la democracia y los ideales revolucionarios. El periodo en cuestión es conocido como el Ternor. Las relaciones de poder y la construcción de discursos que se establecieron durante el an̂o II son nuestro tema de análisis.

Palabras clave: poder, violencia, discursos, representación, revolución, legitimidad

\section{ABSTRACT}

During for year II (July of 1793. June of 1794) of the French Revolution, Maximilien Robespierre, leader of the Jacobinos, to direct the destiny of the rising republic. Strongly influenced philosophic and policily by Jean Jacques Rousseau, Robespierre to exercised the power bias of speech in the Legislative Assembly and exercing the revolutionary violence how mean of safeguard the democracy and the revolutionary ideals. The period in study is known like the Ternor. The relationship of power and the building of speech of power to established during for the year II is our theme of analisys.

Key words: power, violence, speech, representation, revolution, legitimity.

\section{LAS RELACIONES DE PODER A TRAVÉS DE LOS DISCURSOS}

Uno de los teóricos más importantes en torno a las relaciones de poder y su naturaleza es Michel Foucault. Por lo tanto hemos decidido introducir sus puntos de vista y su enfoque teórico en este breve análisis de los jacobinos y su relación con el poder, a fin de expandir la base teórica respecto a la complejidad del poder (o de los poderes) en la politica revolucionaria, pero también cotidiana en el año II. Para empezar, Foucault ${ }^{2}$ plantea que toda situación de poder conlleva intentos de contrapoder; todo esfuerzo por imponer

\footnotetext{
- Este articulo es parte de la tesis de grado titulada Democracia y revolución: estudio preliminar en torno a la filosofia de Jean facques Rousseau y su influencia en Maximilien Robespierre, pretende proyectar posibles linens de investigación a seguir en un estudio posterior en relación a la filosofla de Rousseau, las ideas y acciones de Robespierre y la historia del ańo II de la Revolución francesa durante la dirección jacobina. Por lo tanto, de ninguna manera busca entregar ideas concluyentes con respecto a los temas estudiados, al contrario, se trata sólo de una introducción a ciertas temáticas que nos parecen pertinentes de señalar. Cada una de estas tematicas (poder y violencia) merecen una investigaclón peopia y aparte, sin embargo hemos querido mostrar ciertos enfoques teóricos que, creemos, son una buena base para proyectar una posible posterior investigación. Por lo demás, tales conceptos fueron medulares tanto en la praxis politica de Robespierre como en su interpretación de los libros de Rousseau.

* Profesor de Historia y Geografia Universidad del Bio-Bio, Magister en Historia Univ. de Concepción.

1. Soboul, Aibert. 1987. La Revolución Fnancesa. Principlos ideológicos y protagonistas colectivos. Critica, Barcelona.

2 Ver Fonscault, Michel. 1981 , Un didlogo sobre el poder y otras conversaciones, Alianza Editorial, Madrid.
} 
una determinada legalidad, coexiste simultánea y automáticamente con una o varias ilegalidades. A su vez, el poder esta totalmente ligado al conocimiento, al saber. Para Foucault, hablar del conocimiento desde la marginalidad es hablar, simultáneamente, de una voluntad de saber, de un querer-saber. Este querer saber lo contrapone a la violencia de las ideas admitidas, del Partido tomado que se apropia de la verdad, como fue el caso de los jacobinos en 1793, y que desplaza a su contrario al error, dejándolo allí instalado, se trata, pues, de una violencia idealista. Y precisamente fue esto lo que ocurrió con la dictadura de opinión instaurada por los jacobinos.

Pero, ¿qué es el pođer según Foucault? En primer lugar el poder no es, el poder se ejerce. Y se ejerce en actos, en verbo. No es una esencia. Nadie puede tomar el poder y guardarlo en una caja fuerte. Conservar el poder no es tenerlo a cubierto, ni preservarlo de clementos extraños, es ejercerlo continuamente, como lo hizo Robespierre desde el Comité de Salud Pública; es transformarlo en actos repetidos o simultáneos de hacer, y de hacer que otros hagan o piensen. Tomarse el poder, como lo hizo la Montaña, es tomarse la acción - la idea y el acto-, acto frecuentemente afincado en fuerza y violencia. Pero también podemos ver el poder desde lo que Foucault llamaba la microfísica del poder, que era el estudio de la dispersión de las relaciones de poder dentro de la sociedad en su conjunto. No obstante, la forma de ejercicio del poder central supone condiciones sociales para su posibilidad a la vez que produce nuevas configuraciones sociales, $\mathrm{Y}$ estas configuraciones sociales, constituidas a partir de un ejercicio específico del poder, imponen nuevas normas y reglas de comportamiento individual. Esto precisamente fue lo que trató de imponer Robespierre durante su mandato: reglas de comportamientos individuales a través de discursos de poder construidos por él y sus ayudantes, pero originados en las ideas políticas de Rousseau ${ }^{3}$. Trató de imponer la virtud.

Pero, ¿cómo construyó discursos de poder Robespierre? Indudablemente que no es fácil contestar esta pregunta, y menos aun dentro de este artículo. Las respuestas exigen toda una investigación independiente que superan los límites de nuestro estudio. Sin embargo, podemos adelantar algo. Creemos que Robespierre y los jacobinos construyeron discursos de poder a través de dos lineamientos generales: el poder de la virtud y el poder del conocimiento. Robespierre construyó su discurso monopolizando la virtud. Es un discurso moral, donde él y sus seguidores decian tener el poder moral para dirigir la revolución, ya que ellos eran los virtuosos, los seguidores del maestro Rousseau, su guia espiritual. Cuestionarlos a ellos era cuestionar la moral revolucionaria. Ellos eran los "incorruptibles", los fervientes combatientes en contra de todos los vicios, los opositores en contra de la corrupción y las costumbres decadentes. Eran los guardianes de la moral y las costumbres adecuadas al comportamiento revolucionario. Su poder era un poder metafísico, provenía desde una abstracción mayor, desde una idea suprema: la idea de que la virtud era esencial para ejercer sobenanía popular, de que la virtud legitimaba. Por eso, incluso se debia matar por virtud, eliminar a todo aquel que atentara contra ella. Y la virtud, durante el gobierno revolucionario, era patrimonio jacobino.

La segunda forma era el poder del conocimiento, el poder del saber. La misma relación entre la información y la ideologia en la llustración plantea algunas cuestiones generales acerca de la conexión entre conocimiento y poder. Siguiendo a Foucault, ordenamos el mundo de acuerdo con las categorias que damos por supuestas, sencillamente porque están dadas. Ocupan un espacio epistemológico que es anterior al pensamiento, y por ello tienen un extraordinario poder de permanencia. Cuando nos enfrentamos a una manera extraña de organizar la experiencia, percibimos, sin embargo, la fragilidad de nuestras categorias, y todo amenaza con caer en el caos. Las cosas se mantienen unidas sólo porque pueden acomodarse en un esquema clasificatorio que no es cuestionado. Clasificar, por consiguiente, es ejercer el poder. Y fue esto precisamente lo que hicieron Robespierre y sus camaradas durante el gobierno revolucionario. Clasificar a las personas en revolucionarios y contrarrevolucionarios, burgueses y aristócratas, patriotas y realistas, virtuosos y viciosos. Clasificarlos entre los seguidores de Rousseau y los detractores de Rousseau. Él tenía el poder para hacerlo, decidiendo, de paso, el destino de la vida de los ciudadanos franceses.

Todas las fronteras son peligrosas. Si quedan desprotegidas, pueden ser violadas, nuestras categorias pueden destruirse y nuestro mundo disolverse en el caos. Establecer categorias y vigilarlas, por consiguiente, es cosa seria. En la misma Enciclopedia francesa dirigida por Diderot y D'Alambert, en vez de mostrar como las disciplinas podian dividirse en patrones establecidos, expresaba un intento de trazar la frontera entre lo conocido y lo incognoscible, de tal manera que se eliminaba la mayor parte de lo que los hombres habian creido sagrado en el mundo del conocimiento. Al observar a los filósofos como Rousseau en sus complejos intentos de podar el árbol del conocimiento que habian heredado de sus predecesores, podemos formarnos una

\footnotetext{
${ }^{3}$ En torno a esto ver de Michel Foucault El Orden del Discurso
}

Revista de Historia, año 18, vols. 18-19, 2008-2009, pp. 55-68. 
idea más clara de cuánto estaba en juego en la versión del enciclopedismo de la llustración ${ }^{4}$. Pero el mismo intento de imponer un nuevo orden en el mundo volvió conscientes a los enciclopedistas de la arbitrariedad de todo el ordenamiento. Lo que un filósofo como Rousseau habia unido otro podía desunirlo. Robespierre. algunos años después, sabia esto y no dudó en aplicar la violencia necesaria para evitarlo.

Entonces, uno de los poderes que ejerció Robespierre durante su gobierno fue el poder de la argumentación. Pero el poder consiste también en la capacidad de decidir sobre la vida del otro, en la intervención con hechos que obligan, circunscriben, prohiben o impiden. Quien ejerce el poder de la forma que lo hizo Robespierre se arroga el derecho al castigo y a conculcar bienes materiales y simbólicos. Desde esta posición domina, enjuicia, sentencia y perdona. Al hacerlo acumula y reproduce el poder. Foucault, además, plantea la necesidad de analizar el poder más allá de la regla, la ley, la prohibición; de lo permitido y lo prohibido. Rastrea elementos de análisis del poder en sus mecanismos positivos y los encuentra, entre otros, en Marx; destaca que en el fondo no existe un poder, sino varios poderes. Poderes quiere decir formas de dominación, formas de sujeción, que operan localmente. Todas estas formas de poder son heterogéneas. No podemos entonces, desde esta perspectiva, hablar del poder, sino que debemos hablar de los poderes o intentar localizarlos en sus especificidades históricas y geográficas. $\mathrm{Y}$ es eso lo que hemos intentado hacer en este breve análisis del poder jacobino durante la revolución. Verlo en su contexto histórico y social, condicionado por las circunstancias más que por los ideales revolucionarios. Nos parece que el poder no es sólo dominio y sujeción; también se genera poder en la afirmación de la existencia sumida, se trata del poder como un hecho positivo que no implica la opresión del otro. Se trata de la "voluntad de poder" que promulgaba Nietzsche. Ahora ¿cuál y cómo fue el poder ejercido por los jacobinos y Robespierre en el año III? No es fácil identificarlo, pero para hacerlo debemos partir de la premisa de que el poder se mantiene por la hegemonia: dialéctica de consenso y cocrción. Y es a la vez el método de construcción de esa hegemonía.

A través del enfoque de Foucault se intenta encontrar a partir del discurso cuáles son las intencionalidades del sujeto hablante (en este caso Robespierre). Por eso él dice que "el poder no está, por tanto, al margen del discurso. El poder no es ni fuente ni origen del discurso. El poder es algo que opera a través del discurso, puesto que el discurso mismo es un elemento en un dispositivo estratégico de relaciones de poder" . El mismo Foucault nos confirma que "a finales del siglo XVIII, la sociedad instauró un modo de poder que no se fundaba en la exclusión sino en la inclusión en un sistema en el que cada uno debia ser localizado, vigilado, observado noche y dia, en el que cada uno debia ser encadenado a su propia identidad" 6 . Ser o no ser revolucionario, ese era el dilema. Tanto Rousseau como Robespierre, como buenos utilitarios, eran parte de esta idea. Por todo esto es pertinente convocar a Foucault en este estudio. Porque él se ocupa y preocupa de la forma en que distintos mecanismos de poder funcionan en la sociedad, entre nosotros, dentro y fuera de nosotros. Porque él está consciente de que "el poder politico no consiste ínicamente en las grandes formas institucionales del Estado, en lo que llamariamos aparato de Estado. El poder no opera en un solo lugar, sino en lugares múltiples: la familia, la vida sexual, la forma en que se trata a los locos, la exclusión de los homosexuales, las relaciones entre los hombres y mujeres...relaciones todas ellas politicas. No podemos cambiar la sociedad a no ser que cambiemos estas relaciones". Y esto nos sirve para ver con mucha mayor atención como Robespierre ejerció el poder tratando de "educar" al pueblo, reconstituyendo la familia, condicionando las relaciones genéricas, combatiendo la lujuria y los vicios. Entonces, la pregunta clave es: ¿en qué consisten, en el fondo, las relaciones de poder?

El mismo Foucault afirma que "a partir de la Revolución francesa, a partir de finales del siglo XVIII y principios del XIX. En ese momento, observamos cómo se constituyen regimenes politicos que tienen lazos, no solamente ideológicos, sino orgánicos (incluso diria organizativos) con las filosofias. La Revolución francesa, incluso podemos decir que el imperio napoleónico, establecieron con Rousseau y, de una forma más general, con la filosofía del XVIII, lazos orgánicos ${ }^{\prime 7}$. Se construyó con Robespierre y los jacobinos un Estado filosófico sobre la base de las ideas de Rousseau. Son esos lazos orgánicos los que hemos querido destacar y analizar en este ensayo. Son Estados-filosofias, filosofias que al mismo tiempo son Estados y Estados que se piensan, que se reflexionan, se organizan y definen sus opciones fundamentales a partir de proposiciones filosóficas, en el seno de sistemas filosóficos y como la verdad filosófica de la historia. Son filosofias de la libertad que cambian al ser practicadas. De este modo, hemos visto cómo estas filosofias de la libertad han

4 Darnton, Robert, 2006. "Las filósofos podan el árbol del conocimiento" en La gran matanza de gatos y otros episoutios de la historia de la cultura francesa, Fondo de Cultura Económica. México D. F. p. 195

soucault, M, 1999. Estéfica, ética y hermenétutica. Obras esenciaies, vot. III. Paidós, Darcelona, p. 59

6. Ibid., p. 61

7 bbid., p. 115

Revista de Historia, año 18, vols. 18-19, 2008-2009, pp. 55-68. 
producido, a su vez, formas de poder que han dado paso a formas de terror.

Foucault habla del "poder pastoral" para referirse a cierta forma de poder cristiano. Pero aunque Robespierre era un anticristiano en cierto modo adoptó esa manera de ejercer el poder, el poder como algo positivo, productivo. Para Foucault el poder pastoral es "alimentar, sustentar, dar de comer, conducir hasta las fuentes. permitir beber, encontrar buenos pastos. El poder pastoral es, por lo tanto, un poder que aseguna, al mismo tiempo la subsistencia de los individuos y la del grupo, a diferencia del poder tradicional que se manifiesta. esencialmente, por el triunfo sobre sus sometidos. No es un poder triunfante, es un poder benefactor ${ }^{18}$. Es el poder del padre, manifestado a través de la virtud, del virtuoso que abraza y protege al pueblo, pero sólo al pueblo revolucionario. El pastor debe asegurar la salvación del rebaño, pero también la de todos y cada uno de los individuos. El poder del pastor que tiene autoridad para obligar a la gente a hacer lo necesario para salvarse: salvación obligatoria. Virtud obligatoria. Está en posición de vigilar, de ejercer, en todo caso, una vigilancia y un control continuo. En el caso de Robespierre a través del Comité de Salud (o salvación) Pública y del Comité de Seguridad Nacional ${ }^{9}$.

Otro enfoque teórico esencial para abordar la naturaleza del poder y sus implicancias es el del sociólogo Pierre Bourdieu. Ėl relaciona el poder con el lenguaje, el género y la violencia simbólica. Para Bourdieu, el más simple intercambio linguístico pone en juego una red compleja y ramificada de relaciones de poder históricas entre el hablante, dotado de una autoridad social especifica (en este caso Robespierre), y una audiencia o público que reconoce dicha autoridad de diversos grados (la Convención Nacional o la Asamblea Legislativa), como también ocurre entre los grupos a los que pertenecen respectivamente. Lo que intenta demostrar Bourdieu es que una parte muy importante de cuanto ocurre en las comunicaciones verbales, incluso el contenido mismo del mensaje, permanece ininteligible en tanto no se tome en cuenta la totalidad de la estructura de relaciones de poder presente, aunque invisible, en el intercambio ${ }^{10}$. En consecuencia, lo que Bourdieu intenta desentrañar es el cómo es que se puede "hacer cosas con palabras", cómo es posible que las proposiciones produzcan efectos. Y en el caso de nuestro estudio, cómo los discursos de Robespierre significaron acciones del gobierno revolucionario, o cómo los escritos de Rousseau tuvieron repercusiones en las acciones del mismo Robespierre. Por eso Bourdieu nos dice que "cuando nos detenemos a pensarlo, esta capacidad de hacer que sucedan cosas con las palabras, este poder de dar óndenes y poner orden por medio de palabras es realmente mágico"11. Que mejor ejemplo que la relación entre el Rousseau escritor y el Robespierre lector.

De este modo, el poder simbólico, el poder de constituir lo dado al aseverarlo, de actuar sobre el mundo actuando sobre la representación del mundo, no reside en "sistemas simbólicos" bajo la forma de cierta "fuerza ilocutoria", como dice Bourdieu. Es definido en y por una relación determinada que produce creencia en la legitimidad de las palabras y de la persona que las emite, y sólo opera en la medida en que aquellos que los experimentan reconocen a quienes lo ejercen. Y no tenemos duda de la legitimidad de las palabras de Robespierre en el año II y el grado de credibilidad que dispuso hasta Termidor. $\mathrm{Y}$ ni hablar de la legitimidad de Rousseau durante toda la revolución, desde otra perspectiva. El poder de las palabras, el poder de las ideas, nunca estuvo más presente que en el momento en que Robespierre se dirigia hacia su público. Para explicar esta acción a distancia, esta transformación real efectuada sin contacto físico (como fue el caso de Rousseau y su lector Robespierre), debemos reconstruir la totalidad del espacio social en el que son engendradas las disposiciones y creencias que hacen posible, siguiendo a Bourdieu, la eficacia de la magia del lenguaje 12 . Decir (o escribir) es otra forma de hacer.

Pero los jacobinos liderados por Robespierre también ejercieron el poder a través de la opresión de género. Tema que también puede ser abordado según el enfoque teórico de Pierre Bourdieu, para quien la violencia simbólica, que forma parte de la opresión de género, es, en términos simples, la violencia que se ejerce sobre un agente social con su complicidad. Para Bourdieu, "sobre todo de parte de quienes la sufren. toda dominación simbólica implica una forma de complicidad que no es ni sumisión pasiva a una coerción exterior, ni adhesión libre a valores... lo propio de la violencia simbólica consiste precisamente en que, por parte de quien la sufre, implica una actitud que desafia la alternativa corriente, de libertad-coacción" ${ }^{-13}$. Y

\footnotetext{
1 lbid., p. 138. Ver también Las mallas del poder, en el mismo libro de Foucault citado anteriormente.

- Para una sintesis del pensamiento de Michel Foucault ver el excelente libro de la historiadora alemana Ute Daniel, titulado Compendio de Historia Cuitural. Teorias, pnicticas, palabnas claver. Editorial Alianza, Madrid, 2005. Especificamente las paginas 153 a la 168.

to Bourdieu, Pierre y Wacquant, Loic. 2005. Una invitación a la sociologia reflexiva. Editorial Siglo Veintiuno, Buenos Aires, p. 208.

11 Irid, p, 214

12 roid, p. 215

13 rbid., p. 240
}

Revista de Historia, an̂o 18, vols. 18-19, 2008-2009, pp. 55-68. 
esta es una de las principales diferencias entre la teoria de la violencia simbólica de Bourdieu y la teoria de la hegemonía de Antonio Gramsci: la primera no requiere nada de la "fabricación" activa, del trabajo de "persuasión" que implica la segunda. Bourdieu deja esto en claro cuando afirma que "Za legitimación del orden social no es el producto de una acción de propaganda o imposición simbólica deliberada e intencional: resulta, más bien, del hecho de que los agentes aplican a las estructuras objetivas del mundo social estructuras de percepción y de apreciación salidas de esas mismas estructuras y que tienden a representar el mundo como evidente" 14 .

De este modo, para Bourdieu la forma paradigmática de violencia simbólica es la lógica de la dominación de género. Para él, "el caso de la dominación de género muestra mejor que ningún otro que la violencia simbólica se realiza a través de un acto de conocimiento y de desconocimiento que yace más allá -o por debajo- de los controles de la conciencia y de la voluntad, en las tinieblas de los esquemas del habitus que son al mismo tiempo genéricos y genenadores, es decir, producto y productores de género"15. Por eso, las relaciones de poder mantenidas durante la Revolución entre Robespierre y las mujeres revolucionarias pueden ser abordadas desde esta óptica, tomando en cuenta el comportamiento sumiso de una parte de las mujeres francesas de la época y las ideas sexistas de Rousseau imperantes entre los revolucionarios jacobinos. Y aquí es pertinente volver a la opinión de Bourdieu quien afirma que "la libenación de las mujeres sólo puede provenir de una acción colectiva dirigida hacia una lucha simbólica capaz de desafiar prácticamente el acuerdo inmediato sobre las estructuras encarnadas y objetivas, es decir, una revolución sistemática que cuestione los fundamentos mismos de la producción y reproducción del capital simbálico, y en particular, la dialéctica de pretensión y distinción que está en la raíz de la producción y el consumo de bienes culturales como signos de distinción "16. Y esto precisamente, como hemos visto en el capitulo anterior, no sucedió durante el gobierno revolucionario dirigido por Maximilien Robespierre. La mujer revolucionaria francesa, salvo quizá alguna excepción, nunca atacó el fundamento simbólico, cultural, de su opresión de género. Su lucha fue más bien, y por sobre todo, política.

Siguiendo el análisis propuesto por Bourdieu sabemos que el poder es constitutivo de la sociedad y, ontológicamente, existe en las cosas y en los cuerpos, en los campos y en los habitus (normas sociales), en las instituciones y en los cerebros. Por lo tanto, el poder existe fisicamente, objetivamente, pero también simbólicamente. De este modo, legitimar una dominación es dar toda la fuerza de la razón a la razón del más fuerte. Esto supone una puesta en práctica de una violencia simbólica, violencia eufemizada (presente en cada discurso de Robespierre) y, por lo mismo, socialmente aceptable, que consiste en imponer significaciones, de "hacer creer y de hacer ver" para movilizar, tal como lo hizo el lider jacobino durante el año II. La violencia simbólica, entonces, está relacionada con el poder simbólico, y con las luchas por el poder simbólico ${ }^{17}$. Y este poder simbólico es, en efecto, ese poder invisible que no puede ejercerse sino con la complicidad de los que no quieren saber que lo sufren o incluso que lo ejercen. El poder simbólico es un poder de construcción de la realidad que tiende a establecer un orden gnoseológico: el sentido inmediato del mundo ${ }^{18}$. Es el poder de crear una representación del mundo, el poder que ejerció Robespierre para construir su mundo ideal a partir de la lectura de Rousseau. De acuerdo con Bourdieu, las relaciones de comunicación (como los discursos) son siempre, inseparablemente, relaciones de poder que dependen, en su forma y contenido, del poder material o simbólico acumulado por los agentes (o las instituciones como el Comité de Salud Pública) comprometidos en esas relaciones y que pueden permitir acumular poder simbólico. Desde esta perspectiva, ¿qué tanto poder simbólico tuvo Robespierre? ¿Qué tanto tuvo Rousseau?

El poder simbólico como poder de constituir lo dado por la enunciación, de hacer ver y de hacer creer, de confirmar o de transformar la visión (o representación) del mundo y, por ello, la acción sobre el mundo, por lo tanto el mundo; poder casi mágico que permite obtener el equivalente de lo que es obtenido por la fuerza (física o económica), gracias al efecto especifico de movilización, no se ejerce sino si él es reconocido, es decir, desconocido como arbitrario 19 . El poder símbólico, poder subordinado, es una forma transformada - es decir, irreconocible, transfigurada y legitimada-, de las otras formas de poder. Como dice Bourdieu, se produce una verdadera transubstanciación de las relaciones de fuerza haciendo desconocer-

\footnotetext{
Is Ibid, p. 241.

is Ibid, p 245.

in lbid, P. 248.

17. Bourdieu, Pierte, 2000. Intelectuales, politica y poder. Eudeba, Buenos Aires, p. 10.

Th Ibid., pp. 66.67.

19. Boid., p. 71 .
} 
reconocer la violencia que ellas encierran objetivamente, y transformándolas asi en poder símbólico, capaz de producir efectos reales sin gasto aparente de energía ${ }^{20}$. En definitiva, el poder de los discursos de Robespierre, verdaderos discursos de poder, movilizó a toda una nación, por lo menos durante un año, el año II. Y es el mismo poder simbólico que Rousseau ejerció sobre Robespierre. El poder de ambos no fue otro que el poder de la palabra, el poder inconmensurable que pueden adquirir las ideas ${ }^{21}$

En todo caso, sin dudas que el primer objetivo jacobino era la conquista del poder. Desde la caida de los girondinos hasta la de Robespierre, se desarrolló una fase de hegemonia política, en el transcurso de la cual se ejerció plenamente el poder jacobino, donde las relaciones se tensaron, donde a partir de entonces al centro único del impulso gubernamental correspondió exactamente un "centro único de la opinión pública". De este modo, los jacobinos monopolizaron la construcción de discursos de poder, y fueron fabricando consensos en la sociedad parisina. Es aquí donde el poder comienza a estar cada vez más ligado a la violencia revolucionaria, y es hacia esta dualidad entre poder y violencia donde pondremos nuestra atención.

Étienne Balibar en Violencias, Identidades y Civilidad lleva a cabo un análisis brillante. La tesis principal del filósofo marxista francés es que no existe la no-violencia, ya que para él la violencia es inherente a la sociedad. Asimismo, la violencia aparece cuando se provoca un desequilibrio de poder, y para el autor, la fenomenologia del poder implica una dialéctica "espiritual" entre poder y contrapoder, entre Estado y revolución, entre ortodoxia y herejia. Toda la trayectoria de esa dialéctica esta hecha de actos violentos y de relaciones de violencia. Es pertinente también mencionar que Balibar destaca el debate en torno a la atracción de los intelectuales por la violencia. Aunque indudablemente esto tiene que ver con la transgresión de ciertas prohibiciones. Dice que oímos a historiadores, filósofos, juristas, politólogos discutir con respecto a la violencia, y mayor es nuestro convencimiento de que el principal -acaso único-esquema lógico y retórico que sirye para legitimar la violencia es el de la contraviolencia. Además, el filósofo marxista subraya que el hábito de designar a las formas de violencia más idealistas, más espirituales y aparentemente más "suaves" implicadas en la historia de las instituciones de poder como violencia simbólica es un equívoco notable, en una clara diatriba contra Bourdieu.

A partir de esto, quizás la única forma de detener la violencia es por medio de la violencia. No a través del amor, la paz o la justicia. Sin embargo esto no es tan simple. Y aunque ésta (la violencia) está intimamente ligada al poder, no sólo desde los centros del poder irradia la violencia, ya que ésta se encuentra omnipresente en el accionar humano, libre y cotidiano. El poder no se posee, sino que se ejerce, y todo ejercicio de poder es, de por si, un acto de violencia. Por lo tanto, donde hay poder hay violencia, y a la vez hay crueldad, como una forma de goce de quien ejerce el poder. Esto nos lleva a preguntarnos en torno a la misma naturaleza del ser humano y al concepto del "mal". La violencia pareciera estar intrinsecamente ligada al concepto de hombria, la violencia como expresión de una sexualidad masculina latente (¿Rousseau y Robespierre contra las mujeres revolucionarias?). Ser violento seria ser valiente, bravo, esencialmente viril. El odio a la violencia, y toda acción de contraviolencia conllevan en su interior una acción de violencia. En resumen, Balibar afirma que existen distintos grados en la violencia que acompaña la formulación y la puesta en práctica de los ideales, pero no hay grado cero. No hay, entonces, no-violencia. No deberíamos olvidarlo, nos repite Balibar, mientras nos sublevamos contra el exceso de las distintas formas de violencia 22 .

Sin lugar a dudas, siguiendo a Balibar, nosotros deseamos erradicar la violencia. ¿Pero acaso esa actitud no es de por si muy ambivalente? La no-violencia no necesariamente pone fin a toda interrogante, pues tiene una parte ligada con un esfuerzo que hacemos para odiar el instinto de violencia de nosotros mismos. Habitualmente se piensa que el antídoto contra la violencia es mediante la idealización de sus contrarios: derecho, justicia, respeto, amor. Y esto esta intimamente ligado al problema de la definición de la violencia. ¿Es la violencia lo mismo que el poder o la fuerza? Sin dudas que ninguna reflexión acerca de la violencia histórica y social puede limitarse al examen de las temáticas del poder, por más descentralizada que se la piense. Balibar afirma que si decimos que cierta violencia es "autodestructiva" o irracional, que escapa a la lógica de fines y medios, se debe simplemente a que tenemos la sensación de que ella escapa a la lógica de poder y contrapoder. Dice entonces, siguiendo a Foucault, que hay poder, en incluso un aparato de poder provisto de uno o varios "centros", por más compleja y múltiple que sea su constitución. Y por cierto el poder nunca es simple, nunca es estable, implantado aquí o allá por siempre, en tales o tales otras manos, en forma

* Ibid, p. 72 .

21. Para una introđucción al trabaje sociológico de Pierre Bourdieu ver el texto de Ute Daniel anteriormente citado, especificamente desde las páginas 169 a la 184.

22 Balibas, Etienne. 2005. Vioiencias, Identidades y Ctvilidad. Editorial Gedisa, Barceloma, p. 120.

Revisfa de Historia, anio 18, vols. 18-19, 2008-2009, pp. 55-68. 
de tal o tal otro "monopolio"23. Ante esto, Balibar recurre al término crueldad, y dice que la fenomenología de la violencia debe incluir, a la vez que su relación intrinseca con el poder, su relación con la crueldad, que es algo diferente,

Para Balibar, entonces, parte esencial del problema es comprender por qué el poder (ya sea Estado, dominación colonial, poder de los varones, patronal, etc.) debe ser no sólo violento, impetuoso, brutal, sino también "cruel" (recordemos el Terror), es decir, por qué debe tomar de sí mismo y procurar a quienes lo ejercen un efecto de "goce". Sin embargo, no existe nada similar a un centro de la crueldad, ni siquiera un centro deportado o descentrado. Y saber de donde emerge la crueldad es algo en extremo embarazoso para quien no se sienta dispuesto a desarrollar un razonamiento acerca del mal: entre otros motivos, dice Balibar, por no tener que desarrollar simétricamente un razonamiento acerca del bien ${ }^{24}$.

La dialéctica de la violencia en el poder y de su espíritu propio debe tomar como punto de partida el problema del derecho en sus dos dimensiones: elemento de violencia presente en todo momento en su imposición misma (o "fuerza de ley"), y derecho de una fuerza legal, codificada, de un derecho a ejercer la violencia. Por un lado es la antinomia clásica resultante que el poder de Estado tenga el monopolio de la violencia. Pero en el fondo, lo que se da en llamar "violencia fundacional" y confiere al poder de Estado su carácter absoluto (o de monopolio ideal) necesita para existir no sólo ser idealizado o sacralizado, sino también ser materialmente ejercido, efectivamente puesto en práctica en ciertos lugares y tiempos, en ciertas "zonas" de la sociedad. Por lo tanto, la violencia no puede justificarse más que como una contraviolencia preventiva. Lo que llamamos "violencia", las líneas demarcatorias que trazamos entre conductas reputadas violentas y las que no lo son: todo eso sólo es posible de ser visto y de recibir una denominación retrospectivamente, en la recurrencia anticipadora de la contraviolencia. Ante el análisis de Balibar y pensando en la violencia ejercida por los Jacobinos cabe preguntarnos ¿cuáles fueron las instituciones (aparatos y poderes de Estado, formas de acción revolucionaria o de "contrapoder" o "contrarrevolución") a cuyo respecto circunscribieron la crueldad? Y pensamos en los Comités de Salud Pública y Seguridad General, y específicamente en el Tribunal Revolucionario del Pueblo. En todo caso, siguiendo a Balibar, cuando reflexionemos en torno al gobierno revolucionario y la praxis política de Robespierre no debemos olvidar que no existe la violencia cero, la no-violencia. La violencia es inherente a la sociedad y, más aun, a la revolución.

\section{LA VIOLENCIA Y EL TERROR}

Nuestro objetivo principal es llevar a cabo un análisis de las formas y de los rostros de la violencia, Para esto debemos recordar que el periodo jacobino es conocido como el "Terror", ante esto Hobsbawm nos dice que

los conservadores han creado una permanente imagen del Terror como una dictadura histérica y ferozmente sanguinaria, aunque en comparación con algunas marcas del siglo XX, e incluso algunas represiones conservadoras de movimientos de revolución social-como, por ejemplo, las matanzas subsiguientes a la Comuna de Paris en 1871 , su volumen de crimenes fuera relativamente modesto: 17.000 ejecuciones oficiales en catorce meses. Todos los revolucionarios, de manera especial en Francia, lo han considerado como la primera Repuiblica popular y la inspiración de todas las revueltas subsiguientes. Por todo ello puede afirmarse que fue una época imposible de medir con el criterio humano de cada dia. ${ }^{25}$

Todo ello es cierto. Pero para la sólida clase media francesa que permaneció tras el Terror, éste no fue algo patológico o apocaliptico, sino el único método eficaz para conservar el país. Esto lo logró, en efecto, la República jacobina a costa de un esfuerzo sobrehumano. Es indudable que las circunstancias determinaron el accionar jacobino durante la revolución. Si hubiesen seguido un camino más pacifico y conciliador la historia de la Francia revolucionaria no seria la misma, y el cambio no necesariamente seria para mejor. En junio de 1793 sesenta de los ochenta departamentos de Francia estaban sublevados contra Paris; lo ejércitos de los principes alemanes invadian Francia por el norte y por el este; los ingleses los atacaban por el sur y por el oeste; el pais estaba desamparado y en quiebra. Catorce meses más tarde, toda Francia estaba firmemente gobernada, los invasores habian sido rechazados y, por añadidura, los ejércitos franceses ocupaban Bélgica y

23 Ibid., p. 108.

24 Ibid., p. 110.

25 Hobsbawm, Eric. 2003. La Era de la Revolución, 1789-1848. Editorial Critica, Barcelona p. 76. 
estaban a punto de iniciar una etapa de veinte años de ininterrumpidos triunfos militares ${ }^{26}$. Frecuentemente se olvida esto cuando se condena a Robespierre, los jacobinos y su gobierno.

La República del año II superó crisis inimaginables. Para tales hombres el dilema era sencillo: o el Terror con todos sus defectos desde el punto de vista de la clase media, o la destrucción de la revolución, la desintegración del Estado nacional, y probablemente la desaparición del pais. La caída de Robespierre llevó aparejada una epidemia de desbarajuste económico y de corrupción que culminó en una tremenda inflación y en la bancarrota nacional de 1797. A pesar de todo, la politica jacobina liderada por Robespierre e inspirada por Rousseau fue la que mantuvo a Francia como un territorio unido e independiente, además de salvaguardar la revolución.

Y es aqui donde llega el momento de penetrar en los fundamentos de la violencia jacobina. Karl Marx afirma que la violencia es la comadrona de toda sociedad vieja que lleva en sus entrañas otra nueva. Es, por si misma, una potencia económica. Como sabemos, la teoria marxista describe los intereses comunes de los trabajadores en las sociedades industriales como contrapuestos a los de los capitalistas, de ahí esta definición de la violencia. No obstante, no siempre la violencia ha servido como herramienta de cambio social, ya que también encontramos en el devenir histórico una violencia estructural, conservadora, al servicio del poder en su afän de reprimir los movimientos sociales. Ante esta disyuntiva nos preguntamos qué tipo de violencia fue la ejercida por los Jacobinos de la revolución francesa cuando estos estuvieron en el poder. ¿Fue una violencia estructural? ¿Cuál fue el rol de la violencia en este periodo? ¿Cuáles fueron las caracteristicas principales de esta violencia? ¿Se trató solamente de una violencia política? a partir de estas interrogantes abordaremos el estudio de la violencia en el año II de la revolución, el año en que Robespierre y sus camaradas gobernaron en lo que habría de llamarse, como hemos visto, el Terror.

A nuestro parecer, uno de los análisis más profundos y consistentes en torno a la violencia y su relación con el poder lo encontramos en el texto de Eduardo Grüner, Las Formas de la Espada, al cual haremos referencia tratando de sintetizarlo. Para esto, es necesario identificar dos tesis fundamentales del texto: la primera, gue afirma que la violencia es constitutiva de la práctica política, porque es fundadora de la juricidad estatal ${ }^{27}$. La segunda, que dice que el Estado moderno y el contractualismo son posibles por la renegación de la violencia constitutiva de lo político ${ }^{28}$. Para Grüner, desde Platón a Hobbes, de Maquiavelo a Marx, de Weber a la Escuela de Frankfurt, de Schmitt a Foucault, de Hegel a Sartre, ninguno de ellos se hizo jamás la más mínima ilusión sobre la posibilidad de combatir —o siquiera comprender- los conflictos del poder sobre la base de las buenas intenciones, la buena voluntad o la disposición al diálogo de los sujetos cuyos intereses, materiales o simbólicos, estaban comprometidos en tal conflicto: ni siquiera "bellas almas", como las llama Grūner, de la talla de un Rousseau o un Kant llegaron tan lejos en su optimismo voluntarista como para no ver que las relaciones sociales y politicas están permeadas por la lucha de intereses, la violencia, y eso que Nietzsche llamó la "voluntad de poder". La renuncia al análisis, siempre siguiendo a Grüner, de esta dimensión esencial de la práctica política, atravesada por diversas formas de violencia explicita o implícita, equivale a la renuncia a plantearse de verdad "la naturaleza" de nuestro mundo, de nuestras relaciones sociales y de los sujetos que esas relaciones producen ${ }^{29}$. Todo esto en una clara alusión al postmodernismo que se niega a ver y a entender la violencia como constitutivo de lo político y su carácter de estrategia de dominio.

Para Grüner, la violencia es condición fundacional de la Ley, y desde luego persiste más allá de esa fundación. Pero además, la violencia se incorpora a la Ley, haciendo de esta el único ámbito de aplicación legítima de la violencia: definición esencial del Estado moderno, que, como dirá Max Weber, reclama con pretensión de legitimidad el monopolio del ejercicio de la fuerza dentro de su territorio. A su vez, el derecho (y con más razón el derecho político) no es una mera herramienta del poder: es la forma en la cual la violencia del poder se inscribe en la sociedad para hacerla tolerable y "legitima". Lo politico es violencia inscripta en la legalidad de lo social. La politica es el espacio en el cual se expresa explicitamente la violencia de la lucha de clases que atraviesa sordamente a las relaciones sociales de producción. No se puede negar el origen violento del poder político, cualquiera sea este, provenga de donde provenga.

En cuanto a la segunda tesis de Grüner, la necesidad de ocultar el fundamento violento de la política y el Estado es parte constitutiva de esa misma violencia. Entonces, y ante esto, no es solamente la violencia de ese poder en sí misma lo que debe ser suprimido de la memoria: es la potencia del poder popular (sans-

\footnotetext{
25 Ibial.

I7 Griner, Eduardo. 1997. Las Formas de la Espada; Miserias de la teorla politica de la violencia. Editorial Colihue, Baenos Aires, pp. 31 -38.

21 roid., p. 39-49.

20. Ibid., p. 28.
}

Revista de Historia, afto 18, vols. 18-19. 2008-2009, pp. 55-68. 
culottes o jacobino), cuya paradoja es que siendo poder constituyente, sin embargo, resiste la constitucionalización. Por todo esto, siempre se ha buscado, y se seguirá buscando, el olvido de que en el origen del poder establecido hubo una violencia fundadora y constituyente. Se trata de una operación ideológica por excelencia, de un fenómeno de la subjetividad colectiva y social, y no sólo individual.

En conclusión, Grüner identifica dos clases complementarias pero distinguibles de violencia en el origen de lo politico-estatal: la constituyente y la constitucionalizante, en el sentido de tendiente a detener el movimiento constituyente para estabilizar las normas y reglas de juego más favorable a los nuevos sectores dominantes en la sociedad. Ambas violencias son fundadoras de juricidad, pero la primera, por definición excede el orden jurídico que ella misma a contribuido a fundar, $y$ es ese exceso el que debe ser suprimido por la fuerza o por el "consenso": y frecuentemente el componente de la fuerza queda oculto, disuelto -aunque latente- en el del consenso, a través de ese "olvido social", como lo llama Grüner, que llamamos renegación ${ }^{30}$.

Lo que hace Grüner es analizar la construeción de las relaciones de poder. Al afirmar que la violencia es constitutiva de la politica esta diciendo que gracias a la violencia se mantiene el Estado por medio de la coerción y la coacción. La coerción es la capacidad de ejercer la violencia, la posibilidad de llevarla a la práctica. La coacción, en cambio, es el ejercicio de la violencia, la materialización, y ambas encarnan en el derecho. Para Grüner, la contradicción fundante de la política moderna es que la violencia se hace exclusiva y excluyente. La condición fundante pasa a ser preservadora. $Y$ esto es porque lo que las fuentes de poder temen de la violencia es la aparición de un ente juridico nuevo.

Y el escenario de la violencia esta en los espacios públicos. Grüner, siguiendo con su análisis, piensa que el Estado moderno es la subjetivización de la violencia objetiva. La legitimación política le asigna al Estado el rol de árbitro de la lucha por el poder y los intereses. Se intenta ocultar la imagen de poder constituyente del Estado, ya que el Estado representa los intereses de la élite del poder. Comienza a operar la dominación invisible, se domina la libre voluntad de los sujetos. Las relaciones de poder logran seducir e integrar los intereses de las clases. Por lo tanto, el recurso a la violencia solamente opera cuando están en desequilibrio las relaciones de poder. Esto nos lleva a distinguir entre una violencia sistémica y una violencia reactiva. Y en el siglo XX se produce una profunda crisis de esta subjetivización objetivizante ${ }^{31}$. Por lo cual, cree Grüner, estamos en presencia de una crisis de la subjetivización objetivizante que comenzó con la revolución francesa. De ahi la importancia y la pertinencia de un análisis de la violencia en el periodo jacobino en el poder.

Entonces, ¿cuáles fueron las razones de la violencia jacobina? ¿Por qué luchaban? No es simple responder a estas interrogantes, ya que gran parte de los estudios en torno a estas preguntas se dedican más a enjuiciar y a condenar a los Jacobinos por sus acciones, que a buscar comprenderlos encontrando una racionalidad en su violencia revolucionaria. No obstante, la realidad del Estado jacobino no es tan diferente a las características propias del Estado actual, de hecho el Estado jacobino es parte de los orígenes del Estado moderno, y como tal, su objetivo histórico fue desarrollar un discurso ideológico y un sistema politico institucional capaz de refrendar la impunidad y, con ello, no sólo asegurar las bases de su dominación, sino que también legitimar, en el conjunto de la sociedad francesa revolucionaria, la represión como mecanismo de control social, aunque sea pensando en la revolución. Todo esto ligado a esa fascinación que sienten los hombres por la violencia, que se torna demasiada atrayente en los procesos revolucionarios. Porque la violencia, visible o invisible, es la más antigua forma de acción política conocida. Y, dependiendo de quien la utilice, puede servir para oprimir continentes enteros, pero también puede ser empleada para liberarlos. Se debe tener cuidado con la idea adquirida de que la violencia se expresa simplemente a través de las armas, ya que hay violencia en la mayor parte de los actos humanos.

Uno de los historiadores franceses que mas atención a puesto en el estudio de la violencia revolucionaria jacobina es Michel Vovelle que en su libro Introduccion a la Historia de la Revolución Francesa ${ }^{32}$ afirma que la violencia revolucionaria da ocasión al resurgimiento de conductas muy antiguas y de comportamientos absolutamente novedosos: en su espontaneidad, se inscribe en una tradición en que el salvajismo de los humildes es respuesta a la crueldad de la represión. Recordemos que sólo en 1787 se abolieron las formas oficiales de la tortura para responder a la sensibilidad modificada de las Luces. Pero los parisienses de 50 a 60 años habían sido testigos, como lo señala Volvelle, en 1757, del descuartizamiento de

\footnotetext{
30 Ibid., p. 49.

31. En otras palabras, la subjetivizaciỏn objetivizante de la violencia mencionada por Grüner es cuando el Estado moderno monopoliza la violencia.

32. Vovelle, Michel 1984, Introducclon a la Historia de la Revolución Francesa. Editorial Critica, Barcelona, p. 135.
} 
Damiens, en castigo por la puñalada de que hiciera objeto al rey Luis XV. La violencia está presente en la vida cotidiana.

O como lo grafica el mismo testimonio de Babeuf de julio de 1789 - todavia un mero desconocido -, cuando, a propósito del asesinato del intendente de Paris, que tanto lo conmoviera, escribe la misma noche del hecho, aproximadamente, siguiendo a Vovelle, en estos términos: "nuestros amos nos han hecho tan crueles como ellos, de modo que sólo cosechan lo que sembraron. Hoy ya no tenemos por qué buscar argumentos para justificar tales actos ${ }^{* 33}$; por el contrario, los historiadores han convertido a la violencia, en su doble aspecto subversivo y represivo, en objeto de estudio en la larga duración.

En sus primeras manifestaciones, la Revolución francesa es testigo de una violencia a la vez espontánea y puntual. Bajo los jacobinos, en cambio, se pasará a una violencia planificada y expandida. No se trata de ocultar, aun cuando no podamos explicarlos, ninguno de sus aspectos innobles; nadie discutíria hoy que en ello se expresan miedo, embriaguez - a veces en el sentido estricto del término, sin caer por ello en las facilidades de la historia - y pulsiones sádicas. Como dice Vovelle, "en el fuego de la pasión se encuentra un ardor aplastante que pone al descubierto los paisajes del alma, en ocasiones simples, y en otros muy complejos, de acuerdo con la interpretación que se le dé. Esta instantánea de violencia revela también, sì bien no su versatilidad, al menos su ambigüedad ${ }^{* 34}$.

Es mucho más frecuente, durante la revolución, la destrucción que el robo, puesto que el vandalismo es uno de los lenguajes de la violencia. Lo que domina es la noción de reacción punitiva y de justicia popular o de la calle; a este respecto es muy característico el tribunal improvisado para las masacres. Para el cumplimiento de estas tareas surgen "conductores" de los grupos populares, que, sin ser ellos mismos del pueblo, estaban muy cerca de él. En los sitios en donde se ha podido escribir con precisión su historia, los responsables de la violencia, a juicio de Vovelle, son tanto pequeños burgueses o productores independientes -artesanos o tenderos- como pobres y asalariados: están casados y son padres de familia, a menudo de edad madura. Pero la mujer, como hemos visto, también desempeña su papel específico en las jornadas, motivadas sobre todo por razones económicas, y no únicamente en el papel de marimacho desorbitado ${ }^{35}$.

La violencia parece así una reacción defensiva en la mayoria de los casos, polarizada alrededor de la reacción punitiva y que encuentra justificación en una cierta cantidad de puntos de referencia. Poco a poco va aclarando los objetos y los soportes de su hostilidad: el aristócrata, el refractario, el acaparador, de acuerdo con una codificación en la que, para la multitud, hay determinados estimulos que desempeñan un papel esencial, como la vestimenta, distinta entre el sans-culotte y el aristócrata. La muchedumbre excreta sus mitos, cuyo pivote es el tema del complot. Luego se provee de su simbolismo, cuyas imágenes se van imponiendo. La fractura que se instala entonces en la burguesia revolucionaria (girondinos y jacobinos) cristaliza, por una parte, en este problema: una parte de ella (los jacobinos) no sólo legitima la violencia, sino que teoriza sobre ella, en particular, como bien lo señala Vovelle, en los articulos de Marat, que justifica y alienta una violencia a la vez popular y controlada como único medio para salvar la Revolución: "la libertad nace al calor de la insurrección... $" 36$.

El giro decisivo de la violencia al Terror tiene lugar en el año 1793, o sea cuando los jacobinos asumen el poder. No es que la primera desaparezca -lejos de ello-, pero en cierto sentido se margina, se convierte, en el marco de una lucha implacable, en un encadenamiento de masacres en los frentes abiertos de la guerra civil. El Terror oficializado y teorizado, de 1793 a 1794, recibió su definición de los montañeses en el poder: Robespierre, en el célebre discurso del 5 de nivoso del año II ( 25 de diciembre de 1793), integró la violencia en su justificación del gobierno revolucionario hasta la paz. Las leyes de Pradial del año II, en su paroxismo, precisan las modalidades concretas de la misma. ¿Se puede hablar de un rasgo de mentalidad cuando un sistema institucional hace suya y formaliza la práctica espontánea? Por cierto que sí, en la medida en que, en el calor de la acción emerge una nueva sensibilidad, voluntad punitiva y obsesión del complot en unos, y miedo difuso aunque omnipresente en los otros. Una nueva simbologia subraya el giro: la guillotina, por su aspecto limpio y expeditivo, está en las antipodas de los antiguos métodos e instrumentos de tortura.

Los jacobinos guiados por Robespierre implantaron la violencia por medio de dos organismos de Estado: el Comité de Salud Pública y el Comité de Seguridad Pública. Ambos estaban mayoritariamente

33 Citado por Vovelle en Introducción a la Historia Revoinción Fnancesa. p. 135

34 Vovelle, Michel Introduccián.,., P. 137.

35 Ibid., p. 138.

* Ibid, p. 140

Revista de Historia, afio 18, vols. 18-19, 2008-2009, pp. 55-68. 
compuestos por miembros del club Jacobino. Aun asi, también existió la violencia contrarrevolucionaria llevada a cabo por el "Terror blanco". Ya en la caida, la "corrección" o el asesinato de jacobinos, que tiene lugar golpe a golpe, definen un clima nuevo de inseguridad, de violencia oculta. La violencia en ninguna caso desaparece con la caida de Robespierre. Como dice Vovelle, la aventura de la violencia revolucionaria involuciona, en un último estadio, a una rebelión primitiva atomizada, sin perspectivas; no obstante, no quiere decir esto que se trate de un fenómeno insignificante, ya que es la expresión de un profundo malestar social ${ }^{37}$.

De este modo, la deriva hacia la violencia, tuvo como una de las causas primeras y principales, aunque de ningún modo única, la conflictiva situación inicial, es decir, la existencia en Francia de un poderoso Partido de Resistencia, o mejor dicho, de contrarrevolución, contrario a los deseos y logros de 1789. Además, esta violencia se trataria de actos con un origen en una mentalidad y no en ideas; no olvidemos que el viejo mundo era cruel en su globalidad. La violencia y la crueldad de las masacres con que se sofocaban las revueltas, la violencia de la represión, e incluso de las guerras, común antes de 1789 , son una muestra de la naturalidad de la violencia entre el Estado y los campesinos antes de la revolución, como lo ha demostrado George Rudé en su clásico libro La Multitud en la Historia ${ }^{38}$. En este estudio, el papel que las capas populares juegan durante la revolución, complejo en grado sumo, remite a la originalidad de su pasado sociocultural, en particular a una memoria de sufrimiento y de vulnerabilidad de existencia, solicitada contradictoriamente por la dialéctica de la esperanza y la desilusión.

El terror para los jacobinos era un medio legitimo para llevar a cabo la revolución. Lo afirmaba Robespierre en sus discursos explicando cuales eran las motivaciones del gobierno popular democrático y revolucionario: "el móvil del Gobierno Popular en tiempos de paz es la virtud. Pero en tiempos revolucionarios este móvil es, simultáneamente, la virtud y el terror: la virtud sin la cual el terror seria funesto, el ternor sin la cual la virtud seria impotente. El terror no es sino la justicia rigurosa, raida e inflexible, es, pues, una expresión de la virtud; no es tanto un principio particular, cuanto el resultado del principio general de la democracia aplicado a las necesidades más apnemiantes de la patria...el gobierno de la Revolución es el despotismo de la libertad en la lucha contra la tirania" 39 .

El otro líder jacobino más importante, Louis de Saint-Just, tambièn justificaba el terror con elocuentes argumentos: "una República sólo se sostiene mediante la aniquilación total de todo lo que se le opone..... al comienzo de la Revolución se levantaron voces de clemencia a favor de aquellos que la combatian. La clemencia que entonces perdonó la vida a unos pocos culpables, ha costado la vida a 200.000 personas en La Vendée. Esta clemencia ha hecho necesario destruir ciudades enteras; ella ha expuesto la patria a la total aniquilación. Si hoy volviéramos a practicar la misma clemencia, ello nos podria costar 30 años de guerra civil $^{\prime 40}$. En un contexto de guerra contra las potencias extranjeras y de lucha con el enemigo interno, el contrarrevolucionario, las palabras de Saint-Just poseen una lógica. Fria, maquiavélica, y hasta cruel, pero una lógica necesaria dentro del contexto revolucionario y de la mentalidad jacobina. Para él, no se puede pedir perdón, ni mucho menos perdonar, a los enemigos de la República.

Entonces, ¿por qué extrañarse de los altos niveles de violencia durante la revolución? Y mas aún, cuando miramos el contexto político y social de la época ¿por qué condenarla? Acaso la misma Marsellesa no dice en su estribillo, "ia las armas ciudadanos! fformad vuestros batallones! Marchemos, marchemos, que una sangre impura empape nuestros surcos!"41. Deberiamos recordar esto cada vez que nos horrorizamos por lo ocurrido durante el denominado "Terror". Porque toda violencia revolucionaria tiene su origen en las miserias del pueblo, en el odio de los oprimidos, en el dolor de los desarrapados. Como dice una canción popular de la época revolucionaria, "muriéndote de hambre, muriéndote de frio, pueblo despojado de todos los derechos, en voz baja te desesperas. Mientras el rico insolente, que prescindió de tu bondad, en alta voz se consuela ${ }^{-42}$. Sin penetramos en la génesis de la violencia revolucionaria seguramente podremos encontrar un camino hacia su comprensión.

La violencia revolucionaria se inscribe así no sólo en la naturaleza de la Revolución, que es la dominación provisional de los politico sobre lo social (como la interpretaba Marx), sino también en el

In Ibid., P. 143

39 Rudé, Geotge. 1998. La Mulutud en La Historia, Editorial Siglo XXI, México

30 Robespierre, Maximilien. 1990, "Discurso del 7 de febrero de 1794" en La Revoluciśn Francesa en sus Documentos. Rolle, Claudio; Krebs, Ricardo y Dussaillant, Jacqueline (directores): Ediciones Universidad Catolica de Chile, Santiago, p. 142.

40 Saint-Just, Louis de; "Discurso en la Convención el 26 de febrero de 1794 " en Docainentos, p. 144.

41 "La Marsellesa" en Documentos, p. 174. La Marsellesa, himno nacional de Francia, fue cornpuesta el 24 de abrif de 1792, por Claude-loseph Rougget de Lisle, capitán francés de ingenieros, que en ese momento se hallaba de guarnición en Estrasburgo

2 "Nueva canción para los suburbios, $1797^{*}$ en Documentos, p. 189. 
desconocimiento, por parte de los actores del drama, de lo que están a punto de lograr. Tomando a la Francia del siglo XVIII por la Roma antigua, se equivocaron de sociedad, y el anacronismo es una de las principales caracteristicas de la ideologia jacobina. La revolución francesa es, para el joven Marx, el nacimiento del Estado moderno ${ }^{43}$, y al igual que Grüner, él opina que este Estado moderno se fundó por medio de la violencia. $\mathrm{Y}$ dentro de un anacronismo que no permitió reconocer las circunstancias y el contexto histórico y social a los líderes jacobinos. En todo caso, para Marx el Terror sigue siendo el gran enigma de la Revolución. ¿Cómo explicar la radicalización política y la intervención brutal de la segunda generación revolucionaria, apoyada por la plebe de las aldeas? Para nada es tarea fácil o simple. Uno de los posibles caminos es ver la dictadura jacobina como emanada de la única clase realmente revolucionaria, la masa innumerable. Para él, "el régimen del Terror sólo sirvió, en Francia, para echar por tierra con sus formidables mazazos las supervivencias feudales, borrándolas como por encanto del suelo francés. La medrosa y prudente burguesia francesa habria necesitado décadas entenas para realizar esta labor. La acción sangrienta del pueblo no hizo más que allanarle el camino" 44 , De este modo, Marx ve todo el terrorismo francés como sencillamente el modo plebeyo de luchar contra los enemigos de la burguesía, contra el absolutismo, el feudalismo y los filisteos.

Otra perspectiva muy interesante que analiza la violencia jacobina durante la revolución es la del destacado historiador Albert Soboul, especificamente en el libro La Revolución francesa: Principios ideológicos y protagonistas colectivos. Su enfoque es evidentemente marxista. Para él, la violencia engendra la historia a través de la lucha de clases. $\mathrm{Y}$ al abordar la violencia jacobina, Soboul afirma que rechazando toda clase de hipocresia, Robespierre reconocia la necesidad de la violencia, la fuerza coactiva. En 1793 se preguntaba ¿hasta cuándo el furor de los déspotas será llamado justicia y la justicia del pueblo barbarie o rebelión? Sólo por medio de la violencia revolucionaria se alcanzarian los objetivos revolucionarios, que Robespierre definió en estos términos: "queremos completar los designios de la naturaleza. llevar a cabo los destinos de la humanidad, mantener las promesas de la filosofia, absolver a la providencia del prolongado reinado del crimen y la tirania " 45 . De esta forma, la dictadura jacobina de salud pública, entendamos por ello el gobierno revolucionario o sencillamente el Estado jacobino, organizó el poder de la burguesía revolucionaria, instaurándola como clase dominante. El gobierno revolucionario pudo desempeñar esta función fundamentalmente gracias a lo que entonces tuvo carácter de Partido, la red de las sociedades populares afiliadas a los Jacobinos de Paris, gracias también al sistema represivo implantado, el Terror, que de ser espontáneo pasó a ser finalmente organizado en violencia de Estado. El gobierno revolucionario pudo así responder a una doble exigencia: aniquilar a la clase adversaria, la aristocracia contrarrevolucionaria, o al menos reducirla a la impotencia; ampliar los intereses de clase de la burguesía revolucionaria a los intereses comunes entre ella y las capas populares del Tercer Estado, poner a estas masas en movimiento y conducirlas a la lucha hasta la victoria.

Como hemos visto, contra las personas, la cárcel y la muerte, al igual que cualquier otra práctica revolucionaria, el terror evolucionó, de 1789 a 1794, de la espontaneidad popular a la institución, para acabar convirtiéndose en práctica gubernamental y en violencia de Estado. Por otro lado, y siguiendo a Soboul, si pretendemos precisar el balance del Terror, se impone una distinción. El Terror se expresó mediante dos grandes series de medidas, unas preventivas, punitivas otras: la prisión para todo presunto contrarrevolucionario, la muerte para todo contrarrevolucionario confirmado. El gran Terror se desencadenó: cifras entregadas por Soboul indican que de marzo de 1793 al 22 de pradial del año II, 1.251 personas fueron ejecutadas en Paris: 1.375 lo fueron desde el 22 de Pradial al 9 de Termidor. Un testigo de la época afirmaba que "las cabezas caian como las pizarras de los tejados en dias de fuerte viento "46. Ya Marat habia declarado ante la Convención en abril de 1793 que "la libertad debe establecerse a través de la violencia"47.

\footnotetext{
43 Para Marx, las revoluciones de Inglaterra en 1648 y de Francia a partir de 1789 "no representaron el triuryo de una determinada clase de la seciedad sobre el viejo onden politica, sine que prodlamarun el onden politico de la nueva sociedad europea", Ver Marx y la revolución francesa de Francois Futet. 1992. Fondo de Cultura económica. México, p. 204.

4t Citado por Furet en Marx y la Revolucion francesa, p. 46.

4) Soboul, Albert. 1987, La Revoluctón Francesas principios ideológicos y protagonistas colectrivos, p. 339.

4. Ibid., p. 352

a Ibid., p. 326.
}

Revista de Historia, ano 18, vols. 18-19, 2008-2009, pp. 55-68. 


\section{CONCLUSIONES}

En torno a la Historia del Discurso Ilustrado 48 durante la revolución podemos concluir que el carácter del Terror fue el siguiente: se trató esencialmente de un medio de defensa nacional y revolucionario contra la rebelión y la traición. Como la guerra civil, de la que no fue sino un aspecto, cercenó de la nación a los elementos socialmente inasimilables por aristocráticos o porque habian vinculado su suerte a la de la aristocracia. Confirió a los Comités de gobierno la fuerza coactiva que les permitió instaurar la autoridad del Estado revolucionario e imponer a todos la norma de Salud Pública. Contribuyó a fortifícar el sentimiento nacional acallando momentáneamente los egoismos de clase. En particular, permitió imponer la economía dirigida necesaria para el esfuerzo de guerra y para la salvación de la nación. A pesar de su degeneración en violencia de Estado, el terror fue en ese sentido un factor de victoria.

$\mathrm{Y}$ al estudiar la violencia, incluso superficialmente como es en este caso, queda expuesta su fatalidad: es inseparable de la revolución, indisolublemente vinculada al enfrentamiento entre las categorias sociales. Dilucidar el desencadenamiento de la violencia, significa explicar, como dice Soboul, "la marcha de las revoluciones". Descubrir una ética de la violencia, significa "justificar la revolución". La violencia revolucionaria es un mal, pero un mal necesario; no obstante, si nos remontamos a los origenes de este mal, le encontramos una justificación.

De este modo, hemos penetrado en diversos enfoques para el estudio de la violencia y el poder, dos categorias de análisis que, creemos, deben ir necesariamente entrelazadas en su estudio. En definitiva, pensamos que el poder significa la probabilidad de imponer la propia voluntad, aun contra toda resistencia y cualquiera que sea el fundamento de esa probabilidad. Y esto precisamente fue lo que hizo Robespierre durante el año II. No obstante, el poder corresponde a aquella habilidad humana no sólo para actuar sino para actuar en concierto. El poder no es nunca la propiedad de un individuo, corresponde a un grupo y mantiene su existencia siempre y cuando el grupo se mantenga unido (cosa que no sucedió con la Montaña, de ahí una de las razones de la pérdida del poder). Cuando decimos que alguien está "en el poder" a lo que nos referimos realmente es que se le ha conferido poder por un cierto número de personas para actuar en su nombre (el caso de Robespierre y la Convención a través del Comité de Salud Pública). El poder no necesita justificación, siendo inherente a la existencia misma de las comunidades politicas; lo que sí precisa es legitimidad. La violencia, por su parte, puede ser justificable (como hemos visto), pero no será nunca legitima. Poder y violencia, aunque fenómenos diferentes, usualmente figuran juntos. La violencia puede destruir siempre al poder; del cañón de un arma uno se puede hacer del mando más eficaz, produciendo la obediencia más instantánea y perfecta. Lo que no puede surgir nunca de ello es poder. En conclusión, en términos políticos, es insuficiente decir que poder y violencia no son lo mismo. Poder y violencia son opuestos; donde uno manda absolutamente, el otro está ausente. La violencia aparece ahí donde el poder está en riesgo, como siempre estuvo durante el gobierno de Robespierre, pero dejada a su propio arbitrio termina produciendo la desaparición del poder. En otras palabras, la violencia fisica o corporal puede destruir poder, pero es absolutamente incapaz de crearlo.

Entonces, violencia y poder (en el sentido de poder legitimo), desde ésta perspectiva son opuestos; No obstante, pueden actuar de forma simultánea. Pero estos son sólo algunos enfoques teóricos introductorios. Llegar a conclusiones finales requiere de un trabajo mucho más especifico y profundo.

\section{BIBLIOGRAFÍA}

Balibar, Étienne. 2005. Violencias, Identidades y Civilidad. Editorial Gedisa, Barcelona.

Bourdieu, Pierre y Wacquant Loïc. 2005. Una invitación a una sociologia reflexiva. Siglo XXI, Buenos Aires.

Bourdieu; Pierre. 2000. Intelectuales, politica y poder. Eudeba, Buenos Aires.

Daniel Ute. 2005. Compendio de Historia Cultural; Teorias, práctica, palabras claves. Alianza, Madrid.

Darnton, Robert. 2006. La gran matanza de gatos y otros episodios en la historia de la cultura francesa.

Fondo de Cultura Económica, México D.F.

Foucault, Michel. 1981. Un diálogo sobre el poder y otras conversaciones. Alianza Editorial.

Foucault, Michel. 1999. Estética, ética y hermenéutica. Obras esenciales, volumen III. Paidós, Barcelona.

48 Para un breve andisis en torno a la Historia del Discurso, su metodologia de trabajo, fuentes y enfoques teóricos ver el ya mencionado estudio de Ute Daniel, especificamente desde las páginas 319 a la 332. 
Grüner, Eduardo. 1997. Las Formas de la Espada; Miserias de la teoria politica de la violencia. Editorial Colihue, Buenos Aires.

Hobsbawm, Eric. 2003. La Era de la Revoluctón. Editorial Critica, Barcelona.

Rolle, Claudio; Krebs, Ricardo y Dussaillant, Jacqueline (directores). 1990. La Revolución Francesa en sus documentos, Ediciones Universidad Católica de Chile, Santiago.

Rudé, George. 1998. La Multitud en la historia. Siglo Veintiuno editores, México.

Soboul, Albert. 1987. La Revolución Fnancesa, principios ideológicos y protagonistas colectivas. Critica, Barcelona.

Vovelle, Michel. 1984. Introducción a la historia de la Revolución Fnancesa. Critica, Barcelona. 